\title{
Be wary of "natural" therapy in gynecological surgery
}

This article was published in the following Dove Press journal:

International Journal of Women's Health

19 June 2013

Number of times this article has been viewed

\author{
Mark Erian' \\ Glenda McLaren² \\ 'Department of Obstetrics \\ and Gynaecology, University of \\ Queensland, Royal Brisbane and \\ Women's Hospital, Herston, \\ ${ }^{2}$ Obstetrician and Gynaecologist, \\ Mater Mothers Private Hospital, \\ University of Queensland, Brisbane, \\ QLD, Australia
}

Correspondence: Mark Erian Department of Obstetrics and Gynaecology, University of Queensland, Royal Brisbane and Women's Hospital, Herston Q4029, Australia

Emailm.erian@uq.edu.au

\begin{abstract}
It is estimated that more than 4 billion people throughout the world use natural herbs for some aspect of primary health care. These over-the-counter medications, commonly referred to as "complementary and alternative medicines," despite their proposed health benefits, may have serious and potentially fatal side effects. This paper presents the case of a patient who underwent a gynecological operation and suffered heavy postoperative bleeding as a result of her taking large doses of oral raw garlic in the weeks prior to her operation and discusses the issue of patients' perioperative intake of herbal supplements. To our knowledge, this is the first paper to demonstrate the relationship between a natural therapy and postoperative bleeding in gynecological surgery. The patient presented with severe postoperative bleeding following a routine, unremarkable vaginal hysterectomy. The bleeding required a multidisciplinary management intervention involving gynecological surgeons, general surgeons, oncology surgeons, hematologists, anesthetists, and intensive care unit specialists. After careful history taking (unfortunately, undertaken postoperatively), it was unanimously agreed that the postoperative hemorrhage was due to the patient's excessive preoperative oral ingestion of raw garlic. The case and brief literature review presented in this paper concern an area of paucity in gynecological surgery and highlight the relationship between a commonly taken over-the-counter herbal medication and postoperative hemorrhage.
\end{abstract}

Keywords: herbs, gynecological surgery, complementary medicines, alternative medicines, postoperative hemorrhage

\section{Case report}

The patient discussed here was a 37 -year-old Caucasian female, para $1+3$. Her only child was a 15 -year-old male born by spontaneous vaginal delivery. The patient had undergone three successive uneventful vaginal pregnancy terminations in the last 5 years prior to her hysterectomy. Her predominant problem was severe menorrhagia, which had persisted over the past 20 years, and was getting progressively worse. Her menstrual cycles were 6-10/28 days, with passage of clots $(++)$, flooding $(++)$, and associated with deep dyspareunia and dysmenorrhea. She had received medical treatment, including the combined oral contraception pill and oral progestogens, and was fitted with a levonorgestrel-containing contraceptive device (Mirena ${ }^{\circledR}$ Bayer Healthcare Pharmaceuticals, Wayne, NJ, USA) (the latter was spontaneously dislocated and her family physician removed it from the vagina 2 months prior to her vaginal hysterectomy).

She continued to bleed uncontrollably per vagina, which prompted her to request a hysterectomy. Preoperative coagulation profile was not performed, as there was no clinical indication (institutional policy). Vaginal hysterectomy with conservation of 
ovaries was performed. The procedure was unremarkable. Four hours following her operation, the consultant gynecologist was contacted, as the patient's blood pressure had dropped to $95 / 60 \mathrm{mmHg}$ and she was anxious, looked pale despite her pulse rate being only 64 per minute, her hemoglobin had dropped to $5.7 \mathrm{~g} / \mathrm{L}$, and her platelet count was $156 \times 10^{\wedge} 9 / \mathrm{L}$ (as opposed to $12.1 \mathrm{~g} / \mathrm{L}$ and $316 \times 10^{\wedge} 9 / \mathrm{L}$, respectively, preoperatively). Urgent laparoscopy was performed to establish the state of affairs, during which a large pool of blood was observed in the pelvis (Figure 1).

Laparoscopic irrigation/suction was performed using $3 \mathrm{~L}$ of Ringer's solution. No specific points of bleeding were observed (Figure 2) and all the pedicles were redone using a combination of laparoscopic suturing and bipolar coagulation diathermy. Hemostasis was satisfactory and a $6 \mathrm{~mm}$ negative-suction (Bellovac ${ }^{\mathrm{TM}}$ Wellspect Healthcare, Pymble, NSW 2073, Australia) drain was inserted into the former pouch of Douglas at the conclusion of the procedure. A fresh blood transfusion was started before and continued during the operation.

Three hours following the laparoscopy, the patient exhibited clinical signs of ongoing intra-peritoneal hemorrhage, and the Bellovac drain rapidly filled with $500 \mathrm{~mL}$ of fresh blood. Urgent laparotomy, through a Pfannenstiel incision, was performed. No specific bleeding points were identified, but the whole area and pedicles were re-sutured. Oxygenated cellulose (Surgicel ${ }^{\circledR}$, Ethicon, Somerville, NJ, USA) was inserted to help platelet aggregation and formation of a large clot. Two consultant general surgeons were called to the operating theater and, in conference with the consultant gynecologist performing the procedure, it was unanimously agreed that the hemostasis was perfect. Irrigation/suction was undertaken using $2 \mathrm{~L}$ of Ringer's solution, two $6 \mathrm{~mm}$ Bellovac

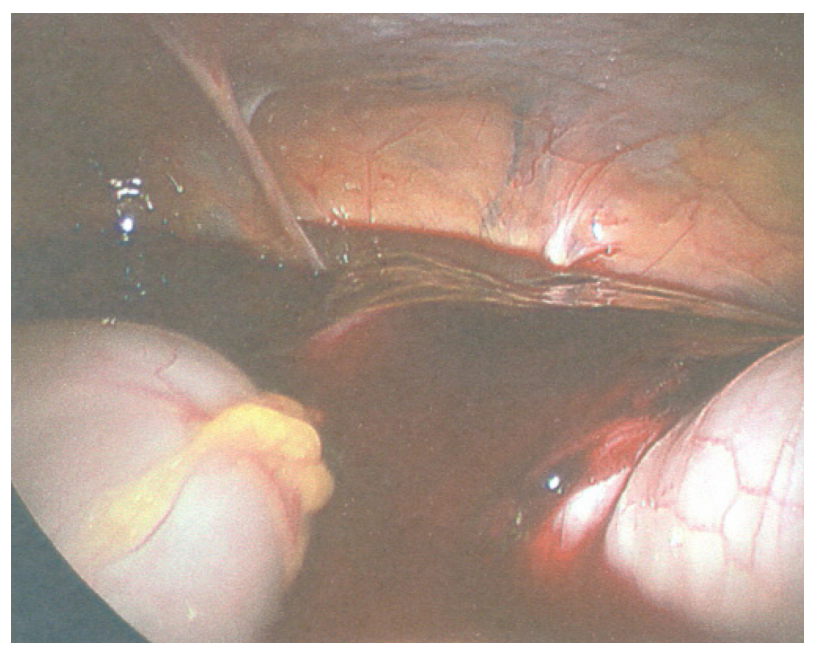

Figure I Laparoscopic photograph showing heavy postoperative bleeding.

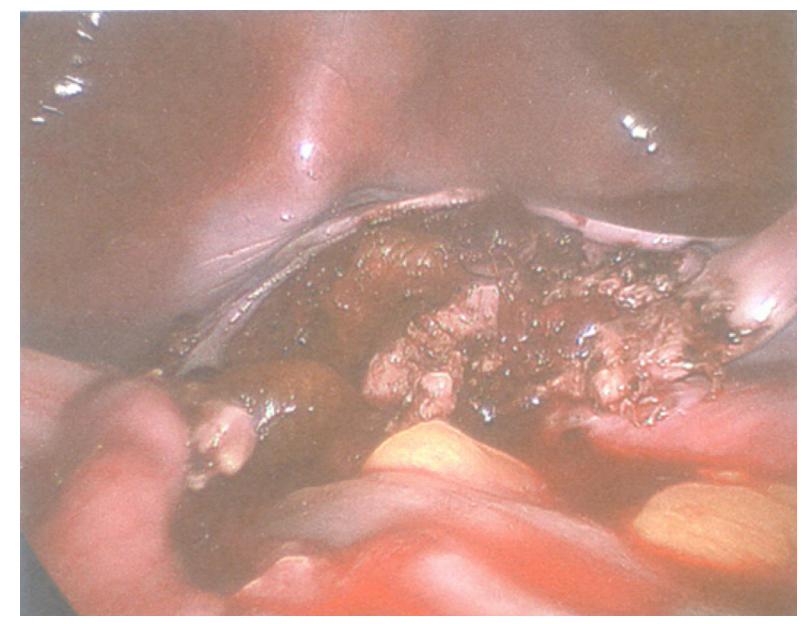

Figure 2 The operation field after laparoscopic irrigation/suction. Note the absence of specific bleeding points.

drains were inserted in the pelvis, and the laparotomy wound was closed. Following the procedure, the patient was sent to the recovery bay in the operating theater.

Over the ensuing 3 hours, the patient's hemoglobin level decreased from 96 to $58 \mathrm{~g} / \mathrm{L}$ and showed a hematological picture consistent with disseminated intravascular coagulopathy. Her international normalized ratio was 1.8 (normal range 0.9-1.3), accelerated partial thromboplastin time was 42 seconds (normal range 25-38 seconds), fibrinogen was $1.2 \mathrm{~g} / \mathrm{L}$ (normal range 1.5-4.0 g/L), and platelet count had dropped to $77 \times 10^{\wedge} 9 / \mathrm{L}$. A consultant hematologist was contacted to manage and monitor the patient's disseminated intravascular coagulopathy situation as it deteriorated further. Three consultant gynecologists, including a gynecology/oncology surgeon, made a combined decision to perform a repeat laparotomy. This time, however, a longitudinal incision was effected to allow freer inspection of all the pelvic-abdominal organs and to exclude bleeding from any unsuspected point(s). Bilateral internal iliac artery ligation and revision of all the previously completed surgical pedicles were performed, followed by irrigation/suction using $2 \mathrm{~L}$ of sterile water, which revealed no active bleeding in the abdomen. Finally, two negative suction drains were inserted in the pelvic-abdominal cavity.

The patient was admitted to the intensive care unit (ICU), and it was there that the reason for her bleeding was surmised. The consultant at the ICU spoke to the gynecologist in charge and enquired about any medication the patient had been taking and the answer was none. However, he then directly asked the patient, "Do you eat a lot of fresh garlic?" She answered, "Oh yes, I have just started my catering business, and I just love eating fresh garlic every day." 
The patient kept draining, via the negative suction system, diminishing volumes of blood over the ensuing 6 days, a decline from $450 \mathrm{~mL}$ of fresh blood on the first postoperative day to only $25 \mathrm{~mL}$ of bloodstained serous fluid on the sixth postoperative day, at which point the decision was made to remove the Bellovac. The patient was discharged 48 hours later with 6 weeks supply of "double" oral iron tablets supplemented with oral vitamin $\mathrm{C}$ to enhance intestinal absorption of the medication. Her general condition was good and her hemoglobin was $86 \mathrm{~g} / \mathrm{L}$ before her discharge from hospital. During her hospitalization, the patient had received a total of 14 units of packed red cells, 16 units of platelets, and eight units of fresh frozen plasma.

In the gynecological outpatient clinic, 6 weeks later, the patient was asymptomatic. Her hemoglobin was found to be $125 \mathrm{~g} / \mathrm{L}$ and her serum iron level was within the normal range. Histological examination of her removed uterus revealed multiple leiomyoma and adenomyosis. The uterus weighed $168 \mathrm{~g}$, with no suggestion of malignancy. At her checkup at 3 months postoperative, the patient continued to show no abnormal symptoms and her hemoglobin was $139 \mathrm{~g} / \mathrm{L}$.

\section{Discussion}

It is estimated that more than 4 billion people throughout the world use natural herbs for some aspect of primary health care $^{1}$ and the use of herbal therapies is on the rise in the Western world. In Australia, for example, $9 \%$ of the population used natural medicines in 1995; in 2000, the prevalence of complementary and alternative medicine (CAM) use ranged between $9 \%$ and $65 \%$; in 2002 , approximately $50 \%$ of the population used CAM; and in 2003, 1.9 million naturopathic and herbal medicine consultations took place in Australia. ${ }^{2-4}$ In the USA, the use of herbal medicines increased by $380 \%$ between 1990 and $1997 ;{ }^{5}$ it is estimated that one in five people in the USA use a herb for treatment of health conditions and/or health promotion ${ }^{6}$ and that $27 \%$ of surgical patients take at least one herbal medicine. ${ }^{7}$ However, CAMs are often not considered by patients as medications and it has been noted that $70 \%$ of patients do not reveal herbal use to their doctors. ${ }^{8}$ As such, surgeons and anesthetists should specifically enquire about the use of CAMs when the patient is being assessed for elective surgery. ${ }^{9}$

Fresh garlic and garlic extracts (Allium sativum) are commonly used to lower blood pressure, blood cholesterol, improve glycemic control, for their antifungal and antimicrobial properties, and to cut short the course of the common cold/influenza. ${ }^{10-14}$ Moreover, Allium increases bleeding time, inhibits platelet aggregation, and exhibits fibrinolytic characteristics. The antiplatelet activities are produced as Allium reduces the formation of thromboxane (which helps platelet aggregation) from arachidonic acid. Phospholipase activity and epinephrine-induced aggregation may also be inhibited, as well as aggregation induced by calcium ionophore A23187, which may be related to intraplatelet mobilization of calcium. ${ }^{15-18}$ The bleeding potential of oral intake of fresh garlic/garlic extracts may be dose related. ${ }^{19}$ However, in the case discussed, the patient had taken about eight cloves of fresh garlic per day for a period of 6 months before the hysterectomy. Her last garlic meal was nearly 12 hours preoperatively. Nevertheless, it was not possible to objectively assess the amount taken.

In Melbourne, Australia, a patient undergoing a strabismus operation suffering from postoperative massive bilateral retrobulbar hemorrhages and elevated intraocular pressures was found to have taken odorless garlic tablets prescribed by a naturopath..$^{20}$ In another case, a spinal epidural hematoma was found to be associated with platelet dysfunction due to excessive garlic ingestion. ${ }^{21}$ Similarly, excessive garlic intake has been associated with bleeding in dermatological ${ }^{22}$ and plastic surgery. ${ }^{23,24}$ Allium sativum is known to interact with warfarin $^{25,26}$ and cases of cerebral hemorrhage - as a result of this interaction - have been reported. ${ }^{27}$

The public's perception is that "natural" therapy is safe ${ }^{28}$ and that there is no harm in taking as many herbs as one wishes $;^{29}$ some patients believe that more is better, which can lead to potential harm from ingesting large quantities of herbal products. In fact, in some countries, herbs are considered more effective than prescribed medicines..$^{30}$ Motivation for herb use is often not based on scientific data. Of herbal users surveyed in the USA, $72 \%$ stated they would continue using herbal supplements despite a negative government study. ${ }^{31}$ Patients often obtain their information about herbs from family, friends, advertisements, and the Internet.

Official regulation of herbal therapy is not always feasible. In 2003, the US Food and Drug Administration required that good manufacturing practices be followed for the dietary supplement industry. The proposed practices require that herbal medicines be properly labeled, free of adulterants, and manufactured according to specified standards for personnel and equipment. ${ }^{32}$ However, there seems to be some practical difficulties in enforcing these recommendations. The World Health Organization (WHO) developed a traditional medicine strategy to promote the integration of traditional and CAM into national health care systems where appropriate..$^{33}$ In addition, the WHO distributed a survey about national policies and regulations for herbal medicine in an attempt 
to frame regulatory policies; enhance quality, safety and efficacy; ensure access; and support the rational use of herbal medicines. Most - 141 of 191 - member states from all WHO regions responded. Over two-thirds of responding countries indicated that they sold herbal medicines without requiring a prescription. Only 37\% of responding nations had herbal medicine regulations in place. ${ }^{34}$

Other widely used herbs include Ginkgo biloba, which is used to slow progression of dementia but is associated with increased bleeding and antiplatelet activity. There have been cases reported of spontaneous severe bleeding following laparoscopic cholecystectomy, ${ }^{35}$ total hip arthropathy, ${ }^{36}$ and liver transplant ${ }^{37}$ after ginkgo ingestion. Ginseng is taken to improve well-being in perimenopausal women and as a mood enhancer, while ginger is used as an antiemetic. ${ }^{38}$ Nevertheless, both are associated with an increased risk of bleeding.

The case reported here was considered the worst case of hysterectomy-related bleeding witnessed by the gynecological and general surgeons involved, who have over 100 years of combined experience between them. Since this "wake-up call," we specifically take herbal history from patients during preoperative assessment and recommend that herbal remedies be discontinued at least 2 weeks prior to elective surgery. ${ }^{39}$ While we recommend that surgeons and anesthetists adopt these practices, we note that this interesting area requires further well-conducted studies employing randomized double-blind methodology.

\section{Acknowledgment}

The authors would like to thank Mrs Ann Hanson, Discipline of Obstetrics and Gynaecology, University of Queensland, for her kind assistance and typing of the manuscript.

\section{Disclosure}

The authors declare no conflicts of interest in this work.

\section{References}

1. Farnsworth NR, Akerele O, Bingel AS, Soejarto DD, Guo Z. Medical plants in therapy. Bull World Health Organ. 1985;63(6):965-981.

2. MacLennan AH, Myers SP, Taylor AW. The continuing use of complementary and alternative medicine in South Australia: costs and beliefs in 2004. Med J Aust. 2006;184(1):27-31.

3. MacLennan AH, Wilson DH, Taylor AW. Prevalence and cost of alternative medicine in Australia. Lancet. 1996;347(9001):369-373.

4. MacLennan AH, Wilson DH, Taylor AW. The escalating cost and prevalence of alternative medicine. Prev Med. 2002;35(2):166-173.

5. Eisenberg DM, Davis RB, Ettner SL, et al. Trends in alternative medicine use in the United States, 1990-1997: results of a follow-up national survey. JAMA. 1998;280(18):1569-1575.

6. Gardiner P, Graham R, Legedza AT, Ahn AC, Eisenberg DM, Phillips RS. Factors associated with herbal therapy use by adults in the United States. Altern Ther Health Med. 2007;13(2):22-29.
7. Norred CL. Complementary and alternative medicine use by surgical patients. AORN J. 2002;76(6):1013-1021.

8. Eisenberg DM, Kessler RC, Van Rompay MI, et al. Perceptions about complementary therapies relative to conventional therapies among adults who use both: results from a national survey. Ann Intern Med. 2001;135(5):344-351.

9. Ang-Lee MK, Moss J, Yuan CS. Herbal medicines and perioperative care. JAMA. 2001;286(2):208-216.

10. Abdullah T. A strategic call to utilize Echinacea-garlic in flu-cold seasons. J Natl Med Assoc. 2000;92(1):48-51.

11. Adetumbi MA, Lau BH. Allium sativum (garlic) - a natural antibiotic. Med Hypotheses. 1983;12(3):227-237.

12. Ali M, Bordia B, Mustafa T. Effect of raw versus boiled aqueous extract of garlic and onion on platelets = aggregation. Prostaglandins Leukot Essent Fatty Acids. 1990;60(1):43-47.

13. Fugg-Berman A. Herbs and dietary supplements in the prevention and treatment of cardiovascular disease. Prev Cardiol. 2000;3(1):24-32.

14. Rahman K, Billington D. Dietry supplementation with aged garlic extract inhibits ADP-induced platelet aggregation in humans. J Nutr. 2000;130(11):2262-2265.

15. Beretz A, Cazenave JP. Old and new natural products as the source of modern antithrombotic drugs. Planta Med. 1991;57(Suppl 7): S68-S72.

16. Neil A, Silagy C. Garlic: its cardio-protective properties. Curr Opin Lipidol. 1994;5(1):6-10.

17. Salman H, Bergman M, Bessler H, et al. Effect of garlic derivative (Alliin) on peripheral blood cell immunity response. Int $J$ Immunopharmacol. 1999;21:589.

18. Williams MJ, Sutherland WH, McCormick MP, Yeoman DJ, de Jong SA. Aged garlic extract improves endothelial function in men with coronary artery disease. Phytother Res. 2005;19(4):314-319.

19. el-Sabban F, Radwan GM. Influence of garlic compared to aspirin on induced photothrombosis in mouse pial microvessels, in vivo. Thromb Res. 1997;88(2):193-203.

20. Carden SM, Good WV, Carden PA, Good RM. Garlic and the strabismus surgeon. Clin Experiment Ophthalmol. 2002;30(4):303-304.

21. Rose KD, Croissant PD, Parliament CF, Lewin MB. Spontaneous spinal epidural hematoma with associated platelet dysfunction from excessive garlic ingestion: a case report. Neurosurgery. 1990;26(5): $880-882$.

22. Chang LK, Whitaker DC. The impact of herbal medicines on dermatological surgery. Dermatol Surg. 2001;27(8):759-763.

23. Burnham BE. Garlic as a possible risk for postoperative bleeding. Plast Rconstr Surg. 1995;95(1):213.

24. Pribitkin ED, Boger G. Herbal therapy: what every facial plastic surgeon must know. Arch Facial Plast Surg. 2001;3(2):127-132.

25. Ramsay NA, Kenny MW, Davies G, Patel JP. Complimentary and alternative medicine use among patients starting warfarin. Br J Haematol. 2005;130(5):777-780.

26. Saw JT, Bahari MB, Ang HH, Lim YH. Potential drug-herb interaction with antiplatelet/anticoagulant drugs. Complement Ther Clin Pract. 2006;12(4):236-241.

27. Evans V. Herbs and the brain: friend or foe? The effects of ginkgo and garlic on warfarin use. J Neurosci Nurs. 2000;32(4):229-232.

28. Skinner CM, Rangasami J. Preoperative use of herbal medicines: a patient survey. Br J Anaesth. 2002;89(5):792-795.

29. Siegel RK. Ginseng abuse syndrome. Problems with the panacea. JAMA. 1979;241(15):1614-1615.

30. Clement YN, Morton-Gittens J, Basdeo L, et al. Perceived efficacy of herbal remedies by users accessing primary healthcare in Trinidad. BMC Complement Altern Med. 2007;7:4.

31. Blendon RJ, DesRoches CM, Benson JM, Brodie M, Altman DE. Americans' views on the use and regulation of dietary supplements. Arch Intern Med. 2001;161(6):805-810.

32. US Food and Drug Administration. FDA announces major initiatives for dietary supplements [news release]. Silver Spring, MD: FDA. Available from: http://www.fda.gov/bbs/topics/news/2004/NEW01130.html. Accessed August 16, 2005. 
33. World Health Organizations. WHO essential drug and medicines policy. Geneva: WHO. http://www.who.int/medicines/library/trm/nationalpolicy_globalsurvey.shtml. Accessed September 9, 2005.

34. World Health Organizations. National Policy on Traditional Medicine and Regulation of Herbal Medicines: Report of a WHO Global Survey. Geneva:WHO; 2005. Available from: http://apps.who.int/medicinedocs/ pdf/s7916e/s7916e.pdf. Accessed May 24, 2013.

35. Fessenden JM, Wittenborn W, Clarke L. Ginkgo biloba: a case report of herbal medicine and bleeding postoperatively from a laparoscopic cholecystectomy. Am Surg. 2001;67(1):33-35.
36. Bebbington A, Kulkarni R, Roberts P. Ginkgo biloba: persistent bleeding after total hip arthroplasty caused by herbal self-medication. Arthroplasty. 2005;20(1):125-126.

37. Hauser D, Gayowski T, Singh N. Bleeding complications precipitated by unrecognized Gingko biloba use after liver transplantation. Transpl Int. 2002;15(7):377-379.

38. Tesch BJ. Herbs commonly used by women: an evidence-based review. Dis Mon. 2002;48(10):371-396.

39. Hodges PJ, Kam PC. The peri-operative implications of herbal medicines. Anaesthesia. 2002;57(9):889-899.
International Journal of Women's Health

\section{Publish your work in this journal}

The International Journal of Women's Health is an international, peerreviewed open-access journal publishing original research, reports, editorials, reviews and commentaries on all aspects of women's healthcare including gynecology, obstetrics, and breast cancer. The manuscript management system is completely online and includes

\section{Dovepress}

a very quick and fair peer-review system, which is all easy to use. Visit http://www.dovepress.com/testimonials.php to read real quotes from published authors.

\footnotetext{
Submit your manuscript here: http://www.dovepress.com/international-journal-of-womens-health-journal
} 